\title{
Detection of uronic acid of Lactobacillus rhamnosus PNO4
}

\author{
Tu K. Nguyen ${ }^{1 *}$ \\ ${ }^{1}$ School of Biotechnology, Hochiminh city International University-Hochiminhcity, National University, Linh Trung ward, Thu Duc District, Vietnam.
}

\begin{tabular}{l} 
ARTICLE INFO \\
\hline Article history: \\
Received on: $31 / 10 / 2013$ \\
Revised on: $26 / 11 / 2013$ \\
Accepted on: $07 / 01 / 2014$ \\
Available online: $20 / 01 / 2014$
\end{tabular}

Key words:

Lactobacillus rhamnosus

PN04, uronic acid, carbazole

assay

\begin{abstract}
Lactobacillus rhamnosus is known as species that had many benefits in pharmaceutical, dairy food industry. To supply more applications for life, the detection of uronic production of Lactobacillus rhamnosus PN04 was done. After the extracellular components of Lactobacillus rhamnosus PN04 culture were precipitated with $1 \%$ cetyl pyridium chloride, the precipitants were used to check the uronic acid production capacity by carbazole assay according to BP98. As a result, the highest uronic acid yield was produced at $96 \mathrm{~h}$ cultivation. The maximum of uronic acid was about $74 \mathrm{mg} / \mathrm{L}$. The study was the first report the uronic acid existing in Lactobacillus rhamnosus PN04.
\end{abstract}

\section{INTRODUCTION}

Lactobacillus rhamnosus is a bacterium that was originally considered to be a subspecies of Lactobacillus casei, but the later genetic research found it to be a species of its own. Some strains of Lactobacillus rhamnosus are being used as probiotics (Coeuret et al., 2007). The species are sometimes presented in yogurt and other dairy products (Coeuret et al, 2003). The most common used Lactobacillus rhamnosus strain is Lactobacillus rhamnosus GG ATCC 3103.

That was isolated in 1983 from the intestinal tract of healthy human being; filed for patent 17 April 1985, by Sherwood Gorbach and Barry Goldin (Gorbach et al., 1989). Lactobacillus rhamnosus GG ATCC 3103 can be used to prevent and treat diarrhea both in children and adults (Canaani et al., 2007; Guandalini et al., 2000). Lactobacillus rhamnosus can be used to treat gastrointestinal disorders caused by vancomycinresistant enterococcus in renal patients (Manley et al., 2007). Additionally, Lactobacillus rhamnosus was found to have antimicrobial effects to pathogens such as Streptococcus sobrinus (Meurman et al., 1995), Salmonella typhimurium (De Keersmaecker et al., 2006).

* Corresponding Author

Tel: 084-8-37244270 ext. 3323

E-mail: nhktu@hcmiu.edu.vn
In order to obtain many benefits of Lactobacillus rhamnosus, the study had detected the uronic acid. This study focused on Lactobacillus rhamnosus PN04 isolated in the plant named Hottuynia cordata Thunb. (Nguyen et al., 2013). Because the source of this strain is from plant, not from intestine or milk found before, it has thought to supply the different applications for life because of the symbiotics.

Uronic acids are constituents of hyaluronic acid that composes of D-glucuronic acid and D-N-acetylglucosamine. It is one of the most potential biological materials and widely used in pharmaceutical and cosmetics. Hyaluronic acid plays an important role in cancer metastasis (Bharadwaj et al., 2007). Uronic acid is also component of glycosaminoglycans used for therapeutic cancer (George et al., 2006). Hyaluronic acid production by Streptococcus zooepidemicus (Vázquez et al., 2010). As the above stated statements, it is necessary to detect uronic acid from the safe source. The study on Lactobacillus rhamnosus PN04 isolated in the plant named Hottuynia cordata Thunb. to bring out many applications so far.

\section{MATERIAL AND METHOD}

\section{Bacteria strains}

L. rhamnosus PN04 was isolated from Hottuynica cordata Thunb (Nguyen et al., 2013). 


\section{Uronic acid isolation}

L. rhamnosus PN04 was cultured in MRS broth (de Man et al, 1960). The starting cell numbers equal to $10^{6} \mathrm{CFU} / \mathrm{ml}$. The cultivation was optimized in difference times at $24 \mathrm{~h}, 48 \mathrm{~h}, 72 \mathrm{~h}, 96 \mathrm{~h}$ and $120 \mathrm{~h}$. The supernatant was collected and precipitated with cetyl pyridinium chloride according to the method of Rosa (Rosa et al., 2007). The 1\% cetyl pyridinium chloride (CPC) (Merck) was added into the supernatant. The reaction was left at room temperature for $24 \mathrm{~h}$. Then, the mixture was centrifuged at 10000 $\mathrm{rpm}$ at $4^{\circ} \mathrm{C}$ for 5 minutes. The pellet was obtained and dissolved in $0.5 \mathrm{ml}$ of $0.9 \mathrm{M}$ sodium chloride $(\mathrm{NaCl})$. Then $1 \mathrm{ml}$ of absolute ethanol was added and the mixture was left for $24 \mathrm{~h}$ at $20^{\circ} \mathrm{C}$. After centrifugation, the supernatant was discarded and the pellet was washed once with $3 \mathrm{ml}$ of $80 \%$ ethanol. The pellet was dried by freeze-dried.

\section{Carbazole assay}

Uronic acid was determined using carbazole calorimetric reagent (Dische, 1946). $500 \mu \mathrm{l}$ of sample was added in the test tube. The tube was cooled in ice-bath, then carefully added with $3 \mathrm{ml}$ of ice-cold sulfuric acid containing borate. The mixture was mixed well and incubated at $100^{\circ} \mathrm{C}$ for $10 \mathrm{~min}$. After incubation, the mixture was cooled in ice bath and $100 \mu \mathrm{l}$ of $0.1 \%$ carbazole (Merck) was added. The mixture was mixed well and incubated at $100^{\circ} \mathrm{C}$ for $15 \mathrm{~min}$. Then, the tube was cooled at room temperature and measured the absorbance at $525 \mathrm{~nm}$. The standard used in the study was D-galacturonic acid (Merck).

\section{High performance liquid chromatography (HPLC) analysis}

Freeze-dried sample was re-suspended in the solution of $1 \mathrm{M}$ sodium chloride, centrifuged and passed through $0.22 \mu \mathrm{m}$ filter membrane. The solutions were analyzed by the HPLC, with C18 column, refractive index detector along with D-galacturonic acid as standard. The mobile phase was the solution of $0.5 \mathrm{M}$ $\mathrm{KH}_{2} \mathrm{PO}_{4}$, pH 2.5 with current speed of $1 \mathrm{ml} /$ minute. Column temperature was maintained at $30^{\circ} \mathrm{C}$.

\section{Statistic analysis}

All of samples were performed triplicate for collect data. And all of datas were analyzed by SPSS 16.0.

\section{RESULTS AND DISCUSSION}

\section{Uronic acid qualification}

After precipitation with cetyl pyridium chloride (CPC), the precipitant was collected after centrifugation and freeze-dried. The weighed biomasses in different times were shown in figure 1 . The highest biomass was produced approximately $2.6 \mathrm{mg}$ for $96 \mathrm{~h}$. The lowest was produced approximately $1.4 \mathrm{mg}$ for $24 \mathrm{~h}$. The biomass amounts increased from $24 \mathrm{~h}$ to $96 \mathrm{~h}$ and then reduced at $120 \mathrm{~h}$ (figure 1). The evaluated biomass were used to qualify the uronic acid. All samples were detected by the reaction to carbazole. The red-purple color appeared in the detected sample (figure 2). The darkest color appeared in the $96 \mathrm{~h}$ sample and the lightest color was appeared in the $24 \mathrm{~h}$ sample. The uronic acid produced in $120 \mathrm{~h}$ was higher than in $24 \mathrm{~h}$ even the biomass was lower. There was the other products precipitated with CPC. More studies should be done.

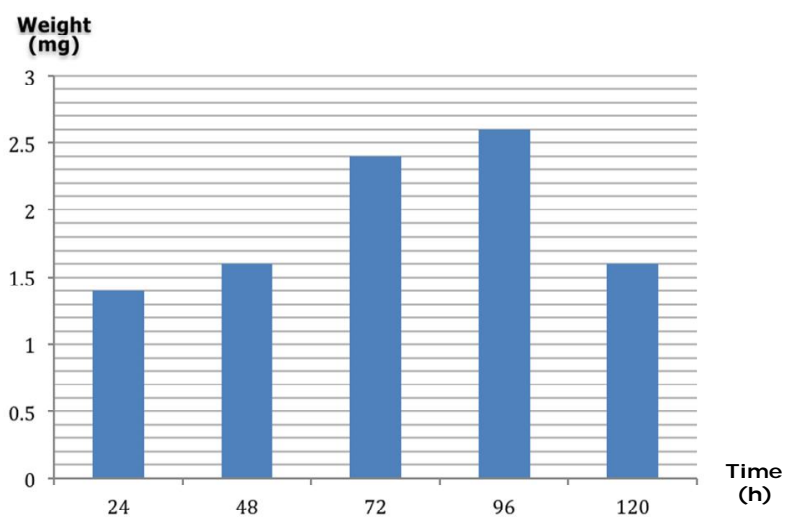

Fig. 1: Biomass collection according to different incubation time.

\section{Uronic acid quantification}

To determine the uronic acid yield, the reaction mixtures were quantitative in different periods (table 1). By carbazole assay, the uronic acid yields in the examined periods were significantly different by statistic analysis. The highest yield was in $96 \mathrm{~h}$ culture (figure 2). The maximum production was $7.4 \mathrm{mg} / \mathrm{L}$. The lowest yield was $0.17 \mathrm{mg} / \mathrm{L}$ in $24 \mathrm{~h}$ culture. The yieds of uronic acid in $48 \mathrm{~h}, 72 \mathrm{~h}, 120 \mathrm{~h}$ were $0.22 \mathrm{mg} / \mathrm{L}, 0.24 \mathrm{mg} / \mathrm{L}$ and $0.37 \mathrm{mg} / \mathrm{L}$, respectively. However, there were no significant differences in the uronic acid yields after 48h, 72h, 120h incubation.

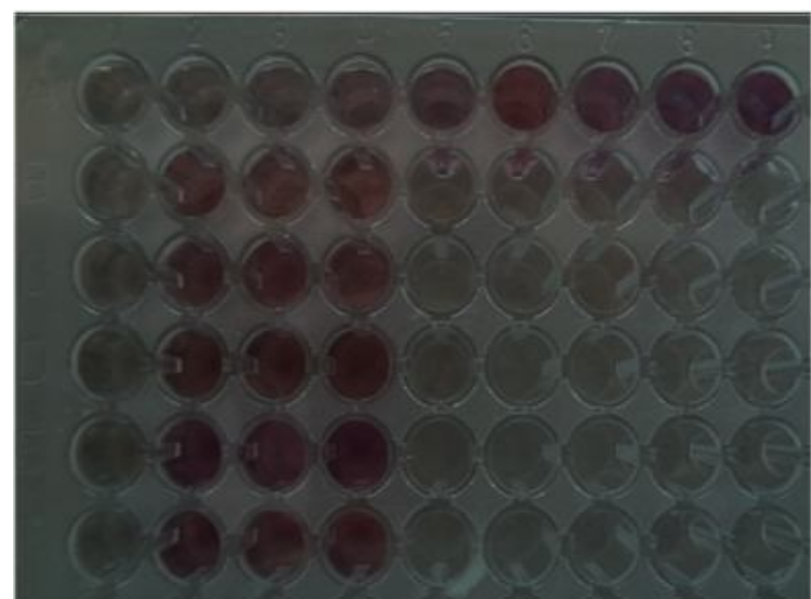

Fig. 2: Carbazole assay results. Wells of $\mathrm{A} 1, \mathrm{~B} 1, \mathrm{C} 1, \mathrm{D} 1, \mathrm{E} 1, \mathrm{~F} 1$ : negative control. Wells of A2, A3, A4, A5, A6, A8, A9: positive control. Wells of B2, B3, B4: Samples of 24h. Wells of C2, C3, C4: Samples of 24h. Wells of D2, D3, D4: Samples of 48h. Wells of E2, E3, E4: Samples of 96h. Wells of F2, F3, F4: Samples of $120 \mathrm{~h}$

Table. 1: The uronic acid measurement in different time.

\begin{tabular}{cc}
\hline Sample & Uronic acid yields $(\mathrm{mg})$ \\
\hline $24 \mathrm{~h}$ & $0.17 \pm 0.02$ \\
$48 \mathrm{~h}$ & $0.22 \pm 0.05$ \\
$72 \mathrm{~h}$ & $0.24 \pm 0.05$ \\
$96 \mathrm{~h}$ & $0.74 \pm 0.1$ \\
$120 \mathrm{~h}$ & $0.37 \pm 0.07$ \\
\hline
\end{tabular}



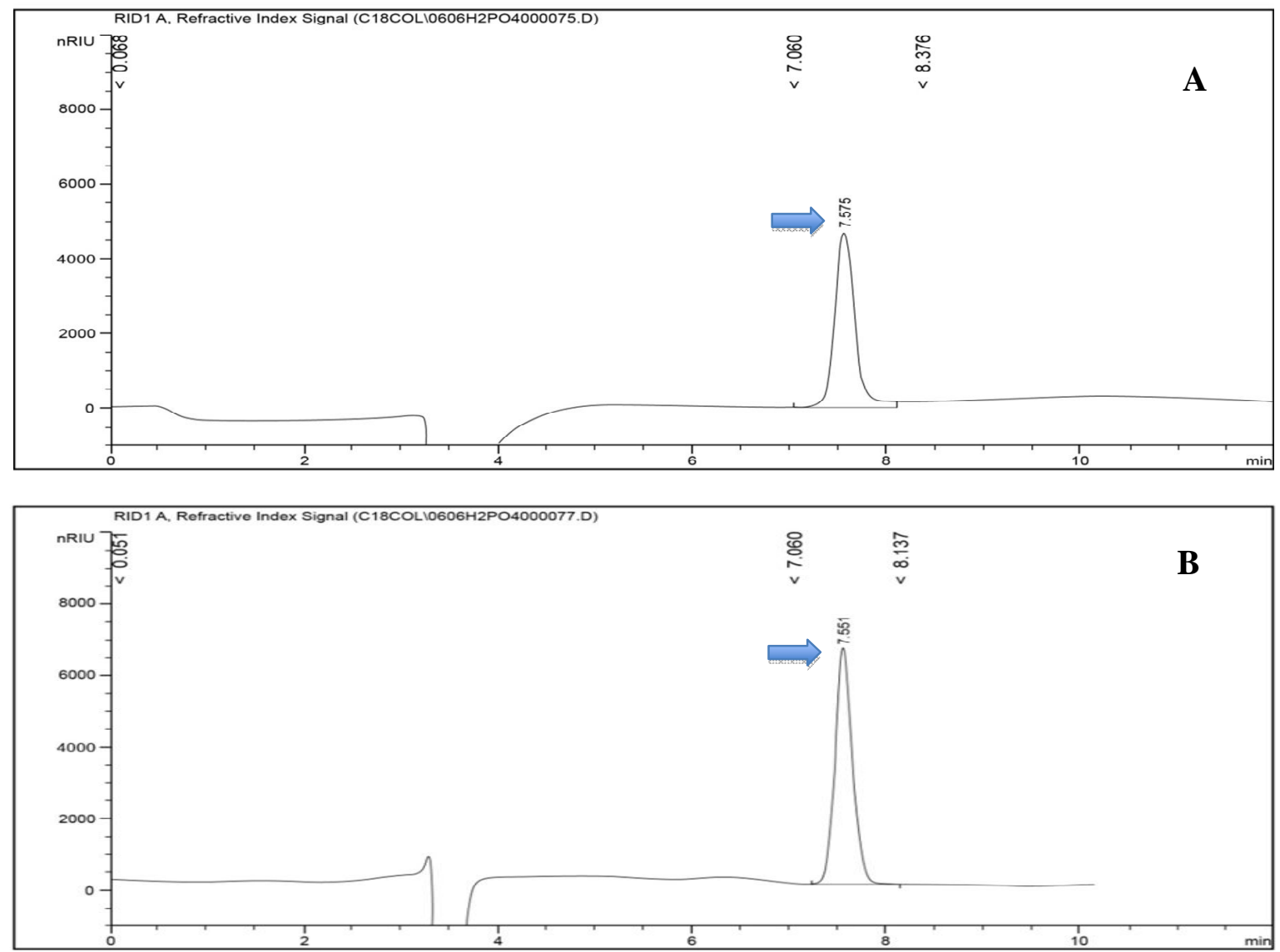

Fig. 3: Results from HPLC analysis. (A) Chromatogram of D-glucuronic. (B). Chromatogram of uronic acid in sample at 96h.

\section{High performance liquid chromatography analysis}

To confirm the uronic acid produced by L. rhamnosus PN04, the supernatant of sample 96h was analyzed by HPLC. In those chromatograms, there were the peaks existed at the similar retention time of 7.575 and 7.561 min corresponding the standard glucuronic acid and tested uronic acid, respectively (figure 3). Therefore, the uronic acid existed in the culture of L. rhamnosus PN04.

\section{CONCLUSION}

In conclusion, the result from this study was showed that uronic acid was detected by growing L. rhamnosus PN04. Detected uronic acid of $L$. rhamnosus PN04 showed that $L$. rhamnosus PN04 might be a potent source for hyaluronic acid and other extrapolysaccharides supplying for pharmaceutical field. To study these compounds in L. rhamnosus, more study should be done.

\section{REFERENCES}

Bharadwaj AG, Rector K, Simpson MA. Inducible Hyaluronan Production Reveals Differential Effects on Prostate Tumor Cell Growth and Tumor Angiogenesis. J Biol Chem, 2007; 282 (28): 2056120572.
Canaani RB, Cirillo P, Terrin G, Cesarano L, Spagnuolo MI, De Vincenzo A, Albano F, Passariello A, De Marco G, Manguso F, and Guarino A. Probiotics for treatment of accute diarrhoea in children: randomised clinical trial of five different preparations. $\mathrm{Br}$ Med $\mathrm{J}$, 2007; 335 (7615): 340

Coeuret V, Gueguen M, Vernoux JP. Numbers and strains of Lactobacilli in some probiotic products. Int J Food Microbiol, 2004; 97: 147- 156 .

Coeuret V, Dubernet S, Bernardeau M, Gueguen M, Vernoux JP. Isolation, characterisation and identification of Lactobacilli focusing mainly on cheeses and other dairy products. Lait, 2003; 83: 269-306.

De Keersmaecker SC, Verhoeven TL, Desair J, Marchal K, Vanderleyden J, Nagy I. Strong antimicrobial activity of Lactobacillus rhamnosus GG against Salmonella typhimurium is due to accumulation of lactic acid. FEMS Microbiol Lett, 2006; 259 (1): 89-96.

De Man JC, Rogosa M, Elisabeth Sharpe M. A Medium for The Cultivation Of Lactobacilli. Journal of Applied Microbiology, 1960; 23 (1): 130-135.

Dische, Z. A new specific color reaction of hexuronic acids. J Biol Chem, 1946; 167: 189-198.

George WY, Martin S, Martin G. Therapeutic value of glycosaminoglycans in cancer. Mol Cancer Ther, 2006; 5: 2139-2148.

Gorbach S, Hill C, Goldin B. Both of mass lactobacillus strains and method of selection. United Stage Patent, 1989; 4: 839.

Guandalini S, Pensabene L, Zikri MA, Dias JA, Casali LG, Hoekstra H, Kolacek S, Massar K, Micetic-Turk D, Papadopoulou A, de Sousa JS, Sandhu B, Szajewska H, Weizman Z. Lactobacillus GG administered in oral rehydration solution to children with acute diarrhea: a multicenter European trial. J Pediatr Gastroenterol Nutr, 2000; 30 (1): 54-60. 
Manley KJ, Fraenkel MB, Mayall BC, Power DA. Probiotic treatment of vancomycin-resistant enterococci: a randomised controlled trial. Med J Aust, 2007; 186 (9): 454-457.

Meurman JH, Antila H, Korhonen A, Salminen S. Effect of Lactobacillus rhamnosus GG (ATCC53103) on the growth of Streptococcus-sobrinus in vitro. Eur J Oral Sci, 2009; 103 (4): 253-258.

Nguyen HKT, Doan TTV, Nguyen NH, Ha DL. Molecular cloning, expression of $\min D$ gene from Lactobacillus acidophilus VTCC B-871 and analyses to identify Lactobacillus rhamnosus PN04 from Vietnam, 2013; 53(4): 385-390.

Rosa CS, Rotta J, Barreto PM, Beirão LH. Extraction, Quantification, And Molar Mass Determination Of Hyaluronic Acid Extracted From Chicken Crest. Brazilian journal of food and nutrition, 2007; 18 (3): 237-240.
Vázquez JA, Montemayor MI, Fraguas J, Murado MA. Hyaluronic acid production by Streptococcus zooepidemicus in marine byproducts media from mussel processing waste waters and tuna peptone viscera. Microb Cell Fact, 2010; 9: 46.

How to cite this article:

$\mathrm{Tu}$ K. Nguyen. Detection of Uronic acid of Lactobacillus Rhamnosus PN04. J App Pharm Sci, 2014; 4 (01): 113-116. 